\title{
PENGARUH TINGKAT RELIGIUSITAS, KUALITAS LAYANAN TERHADAP KEPUTUSAN MENABUNG DAN INFORMASI SEBAGAI VARIABEL MODERATING
}

\begin{abstract}
Irham Pakkawaru*
\section{Abstract}

This study aims to find empirical evidence regarding the effect of the level of religiosity, the quality of service on saving decisions of the Faculty of Economics students in Islamic banking and information as a moderating variable. The sample used was students majoring in economics in the city of Palu. The type of data used is primary data with analysis techniques using multiple linear regression and hypothesis testing using simultaneous analysis ( $\mathrm{F}$ test) and partial ( $\mathrm{t}$ test). The results of this study indicate that simultaneously the level of religiosity and service quality variables significantly influence saving decisions. Partially only the service quality variable (X2) has a significant effect on saving decisions (Y). While the religiosity level variable does not have a significant influence on saving decisions (Y), and Information does not moderate or not as a moderating variable.
\end{abstract}

Keywords: Statistic, Islamic Economy, Service Quality 


\section{A. Latar Belakang}

Perkembangan perbankan di Indonesia saat ini begitu menggembirakan, hal ini ditandai dengan banyaknya berdiri bank-bank yang berbasih syariah. Sejalan dengan majunya perkembangan syariah di Indonesia maka juga pemerintah dalam hal ini sebagai mitra bank juga ikut mendukung kegiatan perbankan.

Di Indonesia sendiri muncul gagasan mengenai bank ayariah pada pertengahan 1970 yang dibicarakan pada seminar Indonesia Timur tengah pada tahun 1974 dan seminar Internasional pada tahun 1976, Bank syariah pertama Di Indonesia adalah bank muamalat yang merupakan hasil kerja sama tim perbankan MUI yang ditandatangani pada tanggal 1 November 1991. ${ }^{168}$

Bank Syariah Di Indonesia secara Konsisten telah menujukan perkembangannnya dari waktu ke waktu kendati belum mencapai 55 dari cetak biru perbankan syariah tahun 2002 untuk dicapai pada tahun 2012. Aset bank terdapat total keseluruhan bank telah adalah $4,81 \%$ pada september 2013. Nilai ini lebih dua kali lipat dibanding pangsa pasar pada awal tahun 2009. ${ }^{169}$

Tabel 1.

Pangsa Perbankan Syariah terhadap total Bank (Posisi Januari 2009) ${ }^{170}$

\begin{tabular}{|l|l|l|l|}
\hline & \multicolumn{2}{|c|}{ Bank Syariah } & Total \\
\cline { 3 - 5 } & Nominal(triliun) & Pangsa & $\begin{array}{l}\text { Bank } \\
\text { (Triliun) }\end{array}$ \\
\hline $\begin{array}{l}\text { Total Asset } \\
\text { per 1 Januari } \\
2009\end{array}$ & 51,8 & $2,24 \%$ & $2.308,0$ \\
\hline
\end{tabular}

${ }^{168}$ Kautsar Riza Salman, Akuntansi Perbankan Syariah Berbasis Psak Syariah (Padang kademia: 2012), 2.

${ }^{169}$ Rizal Yahya Aji Erlangga, Akuntansi Perbankan Syariah Teori dan Praktik Kontemporer(Jakarta; Salemba Empat 2014), 23.

${ }^{170}$ Ibid. 


\begin{tabular}{|l|l|l|l|}
\hline $\begin{array}{l}\text { Total Asset } \\
\text { per September } \\
2013\end{array}$ & 222,7 & $4,81 \%$ & $4.737,3$ \\
\hline
\end{tabular}

Perkembangan pertumbuhan bank syariah juga telah di ikuti oleh perkembangan jaringan kantor perbankan syariah. Pada bulan januari 2009, jumlah BUS adalah sebanyak 5 perusahaan sedangkan jumlah UUS sebanyak 26 unit, dan BPRS sebanyak 132 perusahaan.

Tabel 2

Jaringan Kantor Perbankan Syariah Di Indonesia (Posisi Januari 2009) ${ }^{171}$

\begin{tabular}{|c|c|c|c|c|c|c|}
\hline & 2009 & 2010 & 2011 & 2012 & $\begin{array}{l}\text { Agust } \\
2013\end{array}$ & $\begin{array}{l}\text { Agust } \\
2013 \\
\end{array}$ \\
\hline \multirow{3}{*}{$\begin{array}{l}\text { Bank Syariah } \\
\text { Umum (BUS): } \\
\text { Jumlah Bank }\end{array}$} & & & & & & \\
\hline & 63 & 11 & 11 & 11 & 11 & 11 \\
\hline & 711 & 1.215 & 1.401 & 1.745 & 1.882 & 1.937 \\
\hline \multicolumn{7}{|l|}{$\begin{array}{l}\text { Unit Usaha } \\
\text { Syariah (UUS) }\end{array}$} \\
\hline \multirow[t]{2}{*}{ Jumlah UUS } & 25 & 23 & 24 & 24 & 23 & 23 \\
\hline & 287 & 262 & 336 & 517 & 553 & 558 \\
\hline $\begin{array}{l}\text { Bank } \\
\text { Pembiayaan } \\
\text { Syariah (BPRS) }\end{array}$ & & & & & & \\
\hline
\end{tabular}

${ }^{171} \mathrm{Ibid}$ 


\begin{tabular}{|l|c|c|c|c|c|c|}
\hline Jumlah BPRS & 138 & 150 & 155 & 158 & 160 & 160 \\
\cline { 2 - 7 } Jumlah Kantor & 225 & 286 & 364 & 401 & 398 & 410 \\
\hline
\end{tabular}

Di dalam perjalanannya perkembangan pertumbuhan pendirian bank syariah mengalami kemajuan yang cukup signifikan. Fenomena pertumbuhan pendirian bank-bank syariah di Indonesia perlu kita apresiasi bersama. Sejalan dengan perkembangan tersebut seyogianya perlu ditunjang dengan beberapa aspek dan instrumen yang mendukung seperti sumber daya manusia yang harus ditingkatkan, kualitas pelayanan bank syariah harus lebih ditingkatkan.

Menurut Otoritas Jasa Keuangan pangsa pasar perbankan syariah mencapai 5,16\%-5,3\% terhadap perbankan nasional per september 2016. ${ }^{172}$ Perkembangan perbankan syariah Jauh tertinggal dari negara malaysia. Padahal indonesia merupakan negara mayoritas muslim terbesar di dunia saat ini. Saat ini market share perbankan sraiah di Malaysia mencapai $40-50 \%$ sementara di Indonesia baru mencapai $5 \%{ }^{173}$

Di Sulawesi Tengah menurut Kepala Bank perwakilan sulawei tengah, Purjoko mengatakan bahwa pertumbuhan Bank syariah si sulteng setiap tahun mengalami peningkatan. Dari Segi Asset perbankan syariah triwulan II 2015 mencapai Rp.1.026 triliun atau tumbuh 1,51\%jika dibandingkan triwulan II 2014. Namun jumlah pembiayaan perbankan syariah mengalami penurunan tren pada TW II 2015 sebesar Rp925,95 milyar yang sebelumnya TW II 2014 sebesar 954,3 miliyar,purjoko mengatakan berbagai upaya dilakukan Bank Indonesia untuk meningkatkan dan mengembangkan bank syariah dengan melaksanakan festival syariah beberapa waktu lalu, kemudian meningkatkan kerjasama dengan lembaga atau organisasi Islam,

${ }^{172}$ http: //Finalsial.bisnis.com/read/20160927/90/587449/September 2016 dikutip 4 April 2017.

${ }^{173} \mathrm{http}$ : //finance.detik com/moneter/3211676/ojk market share dikutip 4 April 2017. 
khususnya Pondok pesantren untuk memberdayakan ekonomi syariah. ${ }^{174}$

Melihat fenomena di atas, dimana market share perbankan syariah yang belum optimal, fenomena juga terjadi dikalangan mahasiswa jurusan perbankan syariah dimana mahasiswa tersebut lebih banyak berminat menabung pada bank konvensional. Ada beberapa faktor yang melatarbelakangi mengapa para mahasiswa enggan untuk membuka rekening di Bank syariah. Alasan dari dalam misalnya menurut Desi Fatmawati dalam penelitiannya mengatakan adanya sikap mahasiswa dan faktor religiusitas dari diri mahasiswa tersebut. Adapun faktor dari luar yaitu perilaku konsumen dipengaruhi oleh beberapa faktor antara lain: faktor kebudayaan, kelas sosial, keluarga, status, kelompok/komunitas, usia pekerjaan, gaya hidup dan lain-lain.(Zaki) ${ }^{175}$.

Faktor-faktor ini dapat memberi petunjuk bagi pemasar untuk melayani pembeli secara efektif. selain faktor-faktor yang mempengaruhi dalam membentuk perilaku konsumen yang telah disebutkan tadi,sensisifitas religiutas juga merupakan faktor pembentuk perilaku konsumen tadi. Dalam Islam, perilaku seorang konsumen harus mencerminkan hubungan dirinya dengan Allah SWT, konsumen muslim lebih memilih jalan yang dibatasi oleh Allah SWT dengan tidak memilih barang haram, tidak kikir dan tidak tamak

${ }^{174}$ http: //Sulteng .antara news.com/berita /22380/Bi pertumbuhan bank syariah dikutip 4 April 2017

${ }^{175}$ Zaki Muhammad, Faktor-Faktor yang Mempengaruhi Perilaku Konsumen ( 2010 ) dikutip dalam Atik Masruroh Analisis Pengaruh Tingkat Religiusitas dan Diposibble Income terhadap Minat Menabung Mahasiswa di Perbankan Syariah (Semarang; Tp, 2015), 2. 
supaya kehidupannya selamat baik didunia maupun di akhirat. ${ }^{176}$

Melihat fenomena diatas peneliti tertarik untuk mengadakan penelitian mengenai perbankan syariah dengan judul Pengaruh Tingkat Religiusitas, Kualitas pelayanan terhadap Keputusan Menabung dan Informasi sebagai Variabel Moderating.

Dari uraian latar belakang masalah yang telah diungkapkan diatas dapat diidentifikasi beberapa permasalahan yang muncul. Adapun permasalahan tersebut sebagai berikut:

a) Pertumbuhan bank syariah pesat, tetapi persentase penduduk Indonesia yang menggunakan jasa bank syariah hanya sesikit yaitu $8,64 \%$

b) Image bank syariah sebagai bank Islam hanya mampu mempengaruhi 13,1 juta jiwa warga negara Indonesia yang mayoritas muslim untuk menggunakan bank syariah.

c) Terjadi fluktuatif minat masyarakat kota Palu untuk menabung dan menggunakan jasa perbankan syariah.

d) Gaya hidup islami dan religius belum memberikan pengaruh yang optimal kepada masyarakat untuk menggunakan bank syariah.

e) Masih ditemukan kendala yang menyebabkan mahasiswa kota palu untuk membuka rekening Bank syariah

f) Ditemukan mahasiswa yang merasa malas untuk mebika rekening bank syariah.

\section{B. Kajian Teoretis}

1. Religiusitas

Menurut Atang ${ }^{177}$ dalam bukunya Metodologi Studi Islam menjelaskan bahwa religiusitas itu adalah sikap hidup seseorang berdasarkan pada nilai-nilai yang diyakininya. Religiusitas dalam

${ }^{176}$ Atik Masruroh, Analisis Pengaruh Tingkat Religiusitas dan Diposibble Income terhadap Minat Menabung Mahasiswa Diperbankan Syariah (Semarang:Tp., 2015), 2

${ }^{177}$ Dikutip pada artikel memahami makna religiusitas Islachul Imam (http ;// islachul 08.blogspot.co.id/2014/02/ pada tanggal 04 April 2017 
konteks keislaman pun sudah tersirat dalam ajaran agama Islam dalam proses menjalankan ajaran agama secara kaffah atau menyeluruh. Allah Berfirman dalam Al-Quran surat Albaqarah ayat 208 yaitu:

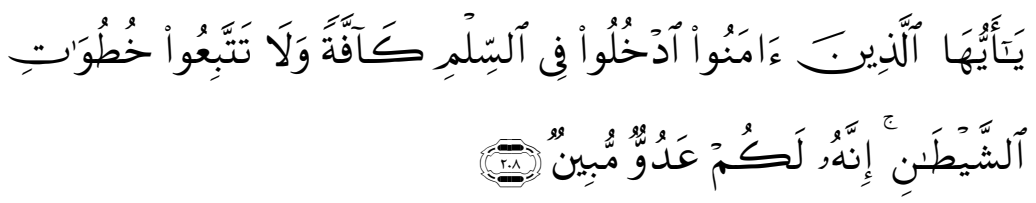

Terjemahnya:

Hai orang-orang yang beriman, masuklah kamu ke dalam Islam keseluruhan, dan janganlah kamu turut langkah-langkah syaitan. Sesungguhnya syaitan itu musuh yang nyata bagimu.

Adapun beberapa pendapat memaknai makna religiusitas dalam makna berperilaku. Dimensi religiusitas dan spiritual memberikan pengaruh dalam bertindak. ${ }^{178}$

Tabel 4

Kesadaran Individu dan Kebiasan Berprilaku

\begin{tabular}{|c|l|}
\hline Kesadaran Spiritual & \multicolumn{1}{|c|}{ Berfungsi } \\
\hline a. Tauhid & Keimanan Kepada Allah yang Haq \\
\hline b. Amanah & $\begin{array}{l}\text { Bukan pemilik yang Asli dari } \\
\text { kehidupan dengan segala atributnya }\end{array}$ \\
\hline c. Pasrah & $\begin{array}{l}\text { Berorientasi zikir yang } \\
\text { menghidupkan kepatuhan atau } \\
\text { ketundukan kepada yang maha kuasa }\end{array}$ \\
\hline d. Fitrah & Segala yang given dan bersih atau \\
\hline
\end{tabular}

${ }^{178}$ Yusuf Qurnia, Quantum Ibadah Mengelola Diri dengan Mengenal Perjalanan Hidup (Solo: Tiga serangkai, 2008), h. 37. 


\begin{tabular}{|l|l|}
\hline & suci dari Allah Maha Pencipta \\
\hline e. Roh/rasa/jiwa & $\begin{array}{l}\text { Sesuatu yang hidup manusia yang } \\
\text { berlawanan dengan hawa nafsu } \\
\text { (kecenderungan sesuatu yang buruk } \\
\text { dan jahat) }\end{array}$ \\
\hline
\end{tabular}

Pada Hakikatnya Faktor kesadaran religiusitas manusia harus lebh tinggi dibandingkan dengan kesadaran emosional sehingga manusia dapat mengendalikan pikirannya. jika kesadaran spiritual manusia lebih tinggi dari pada kesadaran emosionalnya maka seseorang dapat dikendalikan oleh kesadaran spiritualnya.

Manusia pada dasarnya bertanggung jawab atas keputusan yang dibuatnya, namun kontrol yang paling kuat adalah dimensi spiritual dan fakrot religiusitas dalam dirinya. Manusia Diberi akal oleh Allah SWT untuk itu segala sesuatu dan dan keputusannya dipertanggung jawabkan oleh manusia itu sendiri.Allah SWT berfirman pada surah Al Muddatstsir ayat 38

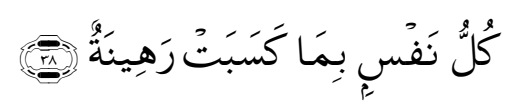

Terjemahnya:

Tiap-tiap diri bertanggung jawab atas apa yang telah diperbuatnya.

2. Kualitas Pelayanan

Salah satu indikator dari sebuah pelayanan adalah kepuasan dari pelanggan, kepuasan juga tergantung pada kualitas produk dan jasa. Kualitas adalah totalitas fitur dan karateristik produk atau jasa yang bergantung pada kemampuannya untuk memuaskan pada kebutuhan yang dinyatakan atau tersirat. ${ }^{179}$

${ }^{179}$ Philip Kotler dan Kevin Lane Keller, Manajemen Pemasaran edisi 3 (Surabaya: Erlangga; 2008), 143. 
Menurut mantan pemimpin GE. John $\mathrm{F}$ welch $\mathrm{Jr}^{180}$ kualitas adalah jaminan terbaik atas loyalitas pelanggan, pertahanan dalam menghadapi persaingan luar negeri dan satu-satunya jalan untuk mempertahankan pertumbuhan dan penghasilan. Adapun Parasuraman, Zeithaml dan Berry dalam Umar tahun 2000 halaman 8-9 untuk mengevaluasi kualitas jasa pelanggan umumnya menggunakan lima dimensi sebagai berikut: ${ }^{181}$

\section{a. Tangibles}

Merupakan bukti nyata dari kepedulian dan perhatian yang diberikan oleh penyedia jasa kepada konsumen. Pentingnya dimensi tangibles ini akan menumbuhkan image penyedia jasa terutama bagi konsumen baru dalam mengevaluasi kualitas jasa. Komponen-komponen tangibels meliputi tampilan fisik seperti gedung, ruangan front office, tempat parkir, kebersihan, kerapian, kenyamanan ruangan dan penampilan karyawan.

b. Reliability

Reliability atau keandalan merupakan kemampuan perusahaan untuk melaksanakan jasa sesuai dengan apa yang telah dijanjikan secara tepat waktu. Pentingnya dimensi ini adalah kepuasan konsumen akan menurun bila jasa yang diberikan tidak sesuai apa yang dijanjikan, jadi komponen atau unsur dimensi Reliability merupakan kemampuan perusahaan dalam menyampaikan jasa secara tepat dan pembebanan biaya secara tepat.

180 Dikutip dalam Philip kotler dan kevin lane keller, manajemen pemasaran edisi 3(Erlangga; 2008)143

181 Dikutip dalam Rizka Ramadhing tyas, pengaruh lokasi dan kualitas pelayanan terhadap keputusan menabung Di BMT Sumber Mulia Tuntang(STAIN Salatiga:2012) 
c. Responsiveness

Responssiveness atau daya tanggap merupakan kemampuan perusahaan yang dilakukan oleh langsung karyawan untuk memberikan pelayanan cepat dan tanggap. Dimensi ini menekankan Pada perhatian dan kecepatan karyawan yang terlibat untuk menanggapi permintaan,pertanyaan,dan keluhan konsumen. Jadi komponen atau unsur dari dimensi ini terdiri dari kesigapan karyawan dalam melayani pelanggan, kecepatan karyawan dalam melayani pelanggan dan penanganan keluhan pelanggan.

d. Assurance

Assurance atau jaminan merupakan pengetahuanem dan perilaku Employee untuk membangun kepercayaan dan keyakinan pada diri konsumen dalam mengkomsumsi jasa yang ditawarkan.Dimensi ini sangat penting karena melibatkan prespsi konsumen terhadap resiko ketidakpastian yang tinggi terhadap kemampuan penyedia jasa.Komponen dari dimensi ini terdiri dari kompetensi karyawan yang meliputi keterampilan, pengetahuan yang dimilki karyawan untuk melakukan pelayanan dan kredibilitas perusahaan yang meliputi hal-hal yang berhubungan dengan kepercayaan konsumen kepada perusahaan seperti,reputasi perusahaan, prestasi dan lain-lain.

e. Emphaty

Emphaty merupakan kemampuan perusahaan yang dilakukan langsung oleh karyawan untuk memberikan perhatian kepada konsumen secara individu,termasuk juga kepekaan akan kebutuhan konsumen. Jadi komponen dari dimensi ini merupakan gabungan konsumen dari akses yaitu kemudahan untuk memanfaatkan jasa yang ditawarkan oleh perusahaan, komunikasi merupakan kemampuan melakukan untuk menyampaikan informasi kepada konsumen atau memperoleh masukan dari konsumen dan pemahaman merupakan usaha untuk mengetahui dan memahami kebutuhan dan keinginan konsumen. 


\section{Keputusan}

Keputusan pemakaian jasa atau lebih dikenal sebagai keputusan pembellian. Keputusan pembelian merupakan suatu proses pengambilan keputusan akan pembelian yang mencakup penentuan apa yang akan dibeli atau tidak melakukan pembelian dan keputusan itu diperoleh dari kegiatan-kegiatan sebelumnya dan Keputusan pemakaian jasa atau lebih dikenal sebagai keputusan pembelian adapun keputusan pembelian merupakan suatu proses pengambilan keputusan akan pembelian yang mencakup penentuan apa yang akan dibeli atau tidak melakukan pembelian dan keputusan itu diperoleh dari kegiatan-kegiatan sebelumnya. ${ }^{182}$

\section{Informasi}

Menurut Jogiyanto Hartono (2004: 692), informasi adalah hasil dari pengolahan data dalam suatu bentuk yang lebih berguna dan lebih berartibagi penerinanya yang menggambarkan suatu kejadiankejadian (event) yang nyata yang digunakan untuk pengambilan keputusan. Informasi dalam menjadi faktor latar belakang, yaitu meliputi pengalaman (experience), pengetahuan (knowledge), dan pemberitaan media massa (media exposure). ${ }^{183}$

Effendy mengemukakan fungsi komunikasi massa secara umum yaitu:

a. Fungsi Informasi

${ }^{182}$ Sofyan Sssauri tahun 2004 dikutip dalam jurnal Muhammad Dwiarisanto dkk, Pengaruh Tabungan dan Kualitas Pelayanan terhadap Keputusan Menabung pada KJKS BMT Bina Ummat Sejahtera Kec. Lasem, h. 31 .

${ }^{183}$ Dikutip dalam penelitian Desy Fatmawati, Pengaruh Pendapatan, Religiusitas dan Informasi terhadap Intensitas Menabung di Bank Syariah pada Kalangan Santri Mahasiswa Pondok Pesantren Wahid Hasyim Sleman (Yogyakarta: 2015), h. 20. 
Fungsi informasi ini diartikan bahwa media massa adalah penyebar informasi bagi pembaca, pengengar maupun pemirsa. Berbagai informasi dibutuhkan oleh khalayak media massa yang bersangkutan sesuai dengan kepentingannya.

b. Fungsi Pendidikan

Media massa banyak menyajikan hal-hal yang sifatnya mendidik seperti melalui pengajaran nilai, etika, serta aturan-aturan yang berlaku kepada pemirsa, pendengan, maupun pembaca.

c. Fungsi Memengaruhi

Media massa dapat memengaruhi khalayaknya baik yang bersifat pengetahuan, perasaan, maupun tingkah laku.

\section{Metodologi Penelitian}

Penelitian ini merupakan penelitan kausal yang bertujuan untuk mengetahui dan menganalisis hubungan antara satu variabel dengan variabel yang lain. ${ }^{184}$ Di dalam penelitian ini penulis menggunakan pendekatan kuantitatif. Metode ini dapat diartikan sebagai metode penelitian yang berlandaskan pada filsafat positivisme, digunakan untuk meneliti pada populasi atau data tertentu.

Teknik pengambilan sampel pada umumnya dilakukan secara random atau insidental sampling, pengumpulan data menggunakan instrumen penelitian, analisis data bersifat kuantitatif/statistik dengan tujuan untuk menguji hipotesis yang telah ditetapkan.Jenis penelitian yang digunakan yaitu metode survey dan deskriptif. Survey adalah suatu metode penelitian yang menggunakan kuestioner sebagai Alat pengumpulan data.

Adapun metode pengumpulan data dalam penelitian ini ada dua macam yaitu kuestioner (angket). Pengukuran variabel menggunakan instrumen berbentuk pertanyaan tertutup, serta diukur dengan menggunakan skala ordinal dari 1 sampai dengan 5. Responden

${ }^{184}$ Husein Umar, Metode Penelitian untuk Skripsi dan Tesis Bisnis (Jakarta: Rajawali Press 2011), 30. 
diminta memberikan pendapat setiap butir pertanyaan mulai dari pertanyaan sangat tidak setuju sampai dengan setuju.

Selain itu, tehnik pengumpulan data selanjutnya adalah dokumentasi yang ditujukan untuk mempeoleh data langsung dari tempat penelitian, meliputi buku-buku yang relevan, peraturanperaturan, laporan kegiatan, foto-foto, film dokumenter maupun data yang relevan dengan penelitian. Adapun sumber data yang digunakan dalam penelitian ini adalah data primer dan data sekunder yaitu data primer yang dikumpulkan dan diolah sendiri oleh suatu organisasi atau perseorangan langsung dari objeknya, serta data sekunder yang diperoleh dari jurnal, majalah, buku, data statistik maupun dari internet. Populasi dalam penelitian ini adalah mahasiswa kota Palu jurusan perbankan syariah dan ekonomi Islam di kota palu berjumlah 1.194 orang. Adapun sampel yang akan digunakan dalam penelitian menggunakan rumus Slovin.

\section{Hasil Penelitian}

1. Hasil Uji Asumsi Klasik

Suatu model dinyatakan baik untuk alat prediksi apabila mempunyai sifat best linier unbiased estimator (BLUE). Di samping itu suatu model dikatakan cukup baik dan dapat dipakai untuk memprediksi apabila telah lolos dari serangkaian uji asumsi ekonometrik yang melandasinya. Uji asumsi klasik dilakukan untuk mengetahui kondisi data yang ada agar dapat menentukan model analisis mana yang paling tepat digunakan.

Uji asumsi klasik dalam penelitian ini terdiri dari uji normalitas, uji multikolineritas, uji heteroskedastisitas dan autokorelasi. Uji normalitas menggunakan normal probability plot yaitu dengan membandingkan data rill dengan data berdistribusi 
normal secara komulatif ${ }^{185}$ dan menggunakan uji Kolmogorof-Smirnov untuk menguji normalitas data secara statistik; uji heteroskedastisitas dengan menggunakan metode chart (diagram Scatterplot) dan gletjser test, uji multikolinearitas dengan menggunakan Variance Inflation Factors (VIF); dan uji autokorelasi dengan menggunakan Durbin Watson statistik.

a. Uji Normalitas

\section{Normal P-P Plot of Regression Standardized Residual}

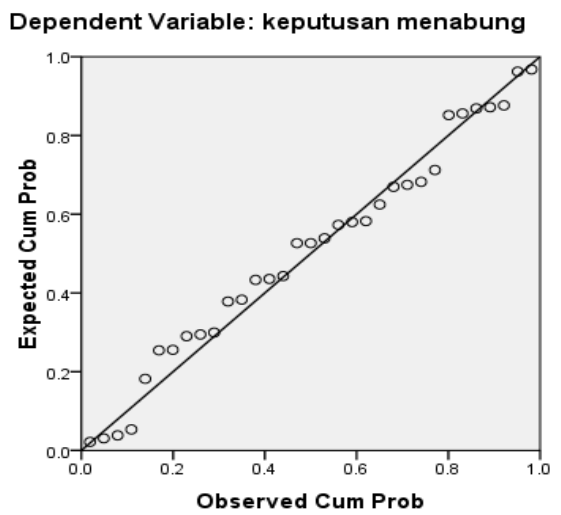

Gambar menunjukkan bahwa data berdistribusi normal. Hal ini dapat dilihat dari titik-titik (garis) yang mengikuti garis diagonal. Jika data menyebar disekitar garis diagonal dan mengikuti arah diagonal, maka model regresi memenuhi asumsi normalitas.

\section{b. Uji Multikolineritas}

Untuk mengetahui ada tidaknya multikolinieritas yaitu dengan mendasarkan pada nilai tolerance dan VIF. Rule of thumb yang digunakan untuk menentukan bahwa nilai tolerance tidak berbahaya terhadap gejala multikoliniearitas adalah 0,10 sedangkan rule of

${ }^{185}$ Danang Sunyoto, Metodologi Penelitian Akuntansi, Cetakan I; (Bandung: Refika Aditama Anggota Ikapi, 2013), h. 68. 
thumbs yang digunakan untuk menentukan bahwa nilai VIF tidak berbahaya adalah kurang dari 10. Hasil uji multikolinearitas dapat dilihat pada tabel VIII berikut:

Tabel 5

Hasil Uji Multikolineritas

\begin{tabular}{|l|c|c|c|}
\hline \multicolumn{1}{|c|}{ Variabel } & Tolerance & VIF & Keterangan \\
\hline $\begin{array}{l}\text { Tingkat } \\
\text { religiusitas }\end{array}$ & 0.959 & 1.043 & $\begin{array}{c}\text { Tidak terjadi } \\
\text { multikolinieritas }\end{array}$ \\
\hline $\begin{array}{l}\text { Kualitas } \\
\text { layanan }\end{array}$ & 0.959 & 1.043 & $\begin{array}{c}\text { Tidak terjadi } \\
\text { multikolinieritas }\end{array}$ \\
\hline
\end{tabular}

Sumber: Data sekunder yang Diolah

Pada tabel di atas dapat dilihat bahwa dari kedua variabel bebas memiliki nilai tolerance diatas 0,10 dan nilai VIF dibawah 10. Maka dapat disimpulkan tidak terjadi mulitikolineritas antar sesama variabel bebas dalam model regresi.

c. Uji Heteroskedastisitas

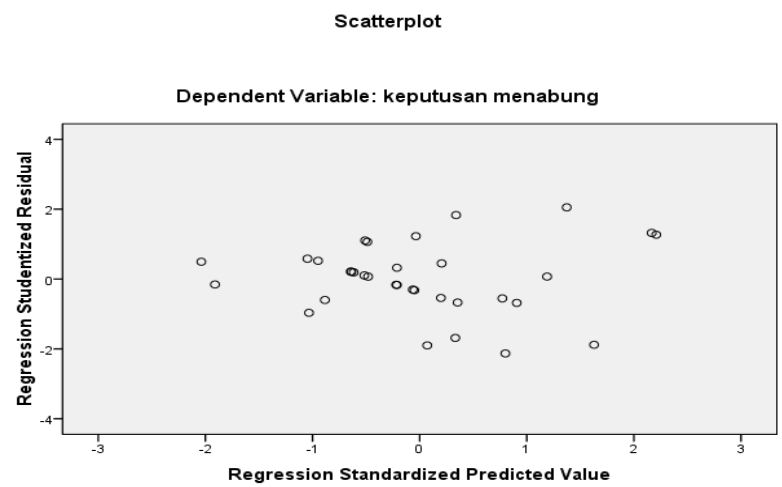


Dari grafik Scatterplots diatas, terlihat bahwa titik-titik menyebar secara acak serta tersebar baik di atas maupun di bawah angka 0 pada sumbu Y. Hal ini dapat disimpulkan bahwa tidak terjadi heteroskedastisitas pada model regresi, sehingga model regresi layak dipakai.

\section{Pengujian Hipotesis}

a. Hasil Analisis Berganda

Metode dan Alat analisis yang digunakan untuk menguji Pengaruh Tingkat Religiusitas, Kualitas Pelayanan terhadap Keputusan Menabung dan Informasi sebagai Variabel Moderating Pengelolaan data yang akan dihasilkan dengan bantuan SPSS 16.0 for windows. Sebagai berikut:

Tabel 6

Koefisien Regresi Uji Signifikasi Coefficients ${ }^{\mathrm{a}}$

\begin{tabular}{|c|c|c|c|c|c|c|c|}
\hline \multirow[t]{2}{*}{ Model } & \multicolumn{2}{|c|}{$\begin{array}{l}\text { Unstandardi } \\
\text { zed } \\
\text { Coefficients }\end{array}$} & \multirow[t]{2}{*}{$\begin{array}{c}\text { Standardi } \\
\text { zed } \\
\text { Coefficie } \\
\text { nts } \\
\text { Beta }\end{array}$} & \multirow[t]{2}{*}{$\mathrm{t}$} & \multirow[t]{2}{*}{ Sig. } & \multicolumn{2}{|c|}{$\begin{array}{c}\text { Collinearity } \\
\text { Statistics }\end{array}$} \\
\hline & B & $\begin{array}{c}\text { Std } \\
\text { Err } \\
\text { or }\end{array}$ & & & & $\begin{array}{c}\text { Toleranc } \\
\mathrm{e}\end{array}$ & VIF \\
\hline $\begin{array}{l}\text { (Consta } \\
\text { nt) }\end{array}$ & 11.010 & $\begin{array}{l}8.4 \\
26 \\
\end{array}$ & & $\begin{array}{l}1.30 \\
7\end{array}$ & .201 & & \\
\hline $\begin{array}{l}\text { tingkat } \\
\text { religiusi } \\
\text { tas }\end{array}$ & -.013 & $\begin{array}{l}.14 \\
9\end{array}$ & -.012 & $\begin{array}{l}- \\
.085\end{array}$ & 933 & 959 & .043 \\
\hline $\begin{array}{l}\text { kualitas } \\
\text { pelayan } \\
\text { an }\end{array}$ & .254 & $\begin{array}{l}.05 \\
2\end{array}$ & .671 & $\begin{array}{l}4.84 \\
6\end{array}$ & 000 & 959 & .043 \\
\hline
\end{tabular}

a. Dependent Variable: Keputusan Menabung

Sumber: Output SPSS 16.0 for Windows Berdasarkan Hasil Penelitian 
Berdasarkan hasil perhitungan pada tabel 4.3 dapat dibentuk suatu model persamaan regresi sebagai berikut:

$$
\mathrm{Y}=11.010+-.012 \mathrm{X} 1+.671 \mathrm{X} 2+\mathrm{e}
$$

Persamaan regresi pada tabel 4.3 memberikan gambaran mengenai pengaruh Tingkat religiusitastterhadap perusahaan terhadap keputusan menabung. Berdasarkan hasil persamaan regresi tersebut, menunjukkan bahwa tingkat religiusiat tidak berpengaruh terhadap keputusan menabung Hal ini terlihat dari $t_{\text {hitung_ }} 0.85$ lebih kecil dari ${ }^{-}$ nilai $t_{\text {tabel }}$ 2,048 atau karena nilai Sig . variabel tingkat religiusitas 0.933 lebih besar dari 0,05 dengan arah koefisien negatif maka disimpulkan bahwa variabel tingkat religiusiat tidak berpengaruh terhadap keputusan menabung.dant Kualitas pelayana pengaruh terhadap keputusan menabung Hal ini terlihat dari $t_{\text {hitun }}$ 4.846lebih besar dari nilai $t_{\text {tabel }} 2,048$ atau karena nilai Sig . variabe kulaitas pelayanan dengan sig 0.000 lebih kecil dari 0,05 dengan arah koefisien positif maka disimpulkan bahwa variabel pelayanan tidak berpengaruh terhadap keputusan menabung.

b. Uji Simultan

Tabel 7

\begin{tabular}{|l|r|r|r|r|l|}
\hline \multicolumn{1}{|c|}{ ANOVA $^{\mathrm{b}}$} \\
\hline Model & Sum of Squares & df & $\begin{array}{c}\text { Mean } \\
\text { Square }\end{array}$ & F & Sig. \\
\hline Regression & 166.552 & 2 & 83.276 & 18.045 & $.000^{\mathrm{a}}$ \\
Residual & 272.286 & 59 & 4.615 & & \\
Total & 438.839 & 61 & & & \\
\hline
\end{tabular}

a. Predictors: (Constant), kualitas layanan, tingkat religiusitas

b. Dependent Variable: keputusan menabung 


\begin{tabular}{|c|c|c|c|c|}
\hline \multicolumn{5}{|c|}{ Model Summary $^{\mathrm{b}}$} \\
\hline Model & $\mathrm{R}$ & R Square & $\begin{array}{c}\text { Adjusted R } \\
\text { Square }\end{array}$ & $\begin{array}{c}\text { Std. Error of the } \\
\text { Estimate }\end{array}$ \\
\hline 1 & $.669^{\mathrm{a}}$ & .448 & .411 & 2.06018 \\
\hline
\end{tabular}

Lebiga. Predictors: (Constant), kualitas pelayanan, tingkat religiusitas

b. Dependent Variable: keputusan menabung

Berdasarkan hasil uji Anova ( Analisis of variace ) Diperoleh F hitung sebesar 18.045 lebih besr dari f tabel 3.307 dengan tingkat signifikasi 0.000 lebih kecil dari 0.05 hal tersebut menujukan bahwa kualitas pelayanan dan tingkat Religiusitas secara simultan berpengaruh terhadap keputusan mahasiswa untuk menabung di Bank Syariah.

c. Uji Residual

Untuk menguji hipotesis keempat dan kelima digunakan uji residual dengan meregresikan variabel tergantung terhadap nilai mutlak residual dari regresi variabel bebas terhadap varibel yang hipotesiskan sebagai variabel yang memoderasi. Jika hasil regresi variabel bebas terhadap yang dihipotesiskan sebagai variabel moderasi signifikan dan koefisien bebas regresinya negatif maka dapat disimpulkan bahwa variabel yang yang dihipotesiskan sebagai varibel moderasi benar-benar mampu memoderasi hubungan antara variabel bebas terhadap variabel tergantung.berikut ini disajikan ringkasan hasil uji residual menggunanakan alat bantu program spss 16.00

Hipotesis keemapat diuji mengggunakan uji residual dengan persamaan moderating 1 dan hipotesis kelima diuji dengan menggunakan uji residual dengan persamaan moderating 2 
1) Moderating 1

Tabel 8

Coefficient

\begin{tabular}{|c|c|c|c|c|c|c|c|}
\hline \multirow{2}{*}{ Model } & \multicolumn{2}{|c|}{$\begin{array}{l}\text { Unstandardized } \\
\text { Coefficients }\end{array}$} & \multirow{2}{*}{ 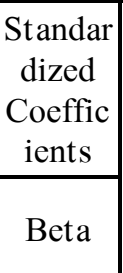 } & \multirow{2}{*}{$\mathrm{t}$} & \multirow{2}{*}{ Sig. } & \multicolumn{2}{|c|}{$\begin{array}{l}\text { Collinearit } \\
\text { y Statistics }\end{array}$} \\
\hline & B & Std. Error & & & & $\begin{array}{c}\text { Toleran } \\
\text { ce }\end{array}$ & $\begin{array}{l}\mathrm{VI} \\
\mathrm{F}\end{array}$ \\
\hline (Constant) & 12.035 & 6.547 & & .838 & 073 & & \\
\hline $\begin{array}{l}\text { tingkat } \\
\text { religiusitas }\end{array}$ & .053 & . 124 & .066 & 426 & 672 & .000 & .0 \\
\hline
\end{tabular}

a. Dependent Variable: informasi

Tabel 9

Coefficients $^{\mathrm{a}}$

\begin{tabular}{|c|c|c|c|c|c|c|c|}
\hline \multirow{2}{*}{ Model } & \multicolumn{2}{|c|}{$\begin{array}{l}\text { Unstandardized } \\
\text { Coefficients }\end{array}$} & \multirow{2}{*}{$\begin{array}{c}\begin{array}{c}\text { Standar } \\
\text { dized } \\
\text { Coeffic } \\
\text { ients }\end{array} \\
\text { Beta }\end{array}$} & \multirow{2}{*}{$\mathrm{t}$} & \multirow{2}{*}{ Sig. } & \multicolumn{2}{|c|}{$\begin{array}{c}\text { Collinearity } \\
\text { Statistics }\end{array}$} \\
\hline & B & $\begin{array}{l}\text { Std. } \\
\text { Error }\end{array}$ & & & & $\begin{array}{c}\text { Toleran } \\
\text { ce }\end{array}$ & VIF \\
\hline (Constant) & 3.787 & 3.461 & & 1.094 & .280 & & \\
\hline $\begin{array}{l}1 \text { keputusan } \\
\text { menabung }\end{array}$ & -.048 & .118 & -.062 & -.405 & .687 & 1.000 & 1.000 \\
\hline
\end{tabular}

a. Dependent Variable: residual 1

Dari kedua tabel diatas dapat ditarik persamaan sebagai berikut:

$$
\text { Informasi } \quad=12.035+0.066 \mathrm{X} 1+\mathrm{E}
$$


I e I $\quad=3.787-0.062$ keputusan menabung

Berdasarkan hasil yang diperoleh pada tabel diatas dimana nilai t hitung yang diperoleh sebesar 0.405 pada taraf signifikansi 0.687 lebih besar dari 0.05 sehingga dapat disimpulkan bahwa variabel informasi bukan merupakan varibel moderating pada hubungan antara tingkat religiusitas terhadap keputusan menabung mahasiswa ekonomi pada bank syariah di kota palu

2) Moderating 2

Tabel 10

Coefficients $^{\mathrm{a}}$

\begin{tabular}{|c|c|c|c|c|c|c|c|}
\hline \multirow{2}{*}{ Model } & \multicolumn{2}{|c|}{$\begin{array}{l}\text { Unstandarded } \\
\text { Coefficients }\end{array}$} & \multirow{2}{*}{ 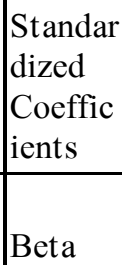 } & \multirow[b]{2}{*}{$\mathrm{t}$} & \multirow[b]{2}{*}{ Sig. } & \multicolumn{2}{|c|}{$\begin{array}{c}\text { Collinearity } \\
\text { Statistics }\end{array}$} \\
\hline & B & $\begin{array}{l}\text { Std. } \\
\text { Error }\end{array}$ & & & & $\begin{array}{l}\text { Toler } \\
\text { ance }\end{array}$ & VIF \\
\hline 1 (Constant) & 9.984 & 5.367 & & 1.860 & .070 & & \\
\hline $\begin{array}{l}\text { kualitas } \\
\text { pelayanan }\end{array}$ & .065 & .072 & 138 & .904 & .371 & 1.000 & 1.000 \\
\hline
\end{tabular}

tabel 11

Coefficients $^{\mathrm{a}}$

\begin{tabular}{|c|c|c|c|c|c|c|c|}
\hline \multirow{2}{*}{ Model } & \multicolumn{2}{|c|}{$\begin{array}{l}\text { Unstandardized } \\
\text { Coefficients }\end{array}$} & $\begin{array}{l}\text { Standardi } \\
\text { zed } \\
\text { Coefficie } \\
\text { nts }\end{array}$ & $\mathrm{t}$ & \multirow{2}{*}{ Sig. } & \multicolumn{2}{|c|}{$\begin{array}{l}\text { Collinearity } \\
\text { Statistics }\end{array}$} \\
\cline { 2 - 6 } & $\mathrm{B}$ & $\begin{array}{c}\text { Std. } \\
\text { Error }\end{array}$ & Beta & & & $\begin{array}{l}\text { Toleran } \\
\text { ce }\end{array}$ & VIF \\
\hline (Constant) & 2.827 & 3.676 & & 769 & .446 & &
\end{tabular}




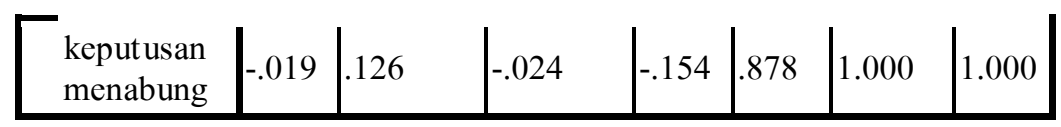

a. Dependent Variable: residual 2

Dari kedua tabel diatas dapat ditarik persamaan sebagai berikut:

$$
\begin{array}{ll}
\text { Informasi } & =9.984+0.138 \mathrm{X} 2+\mathrm{E} \\
\mathrm{I} \text { e I } & =32.827-0.024 \text { keputusan menabung }
\end{array}
$$

Berdasarkan hasil yang diperoleh pada tabel diatas dimana nilai $\mathrm{t}$ hitung yang diperoleh sebesar -.0.154 pada taraf signifikansi 0.878 lebih besar dari 0.05 sehingga dapat disimpulkan bahwa variabel informasi bukan merupakan variabel moderating pada hubungan antara kualitas layanan terhadap keputusan menabung mahasiswa pada bank syariah di Kota Palu.

\section{E. Kesimpulan}

Dari hasil penelitian dan pembahasan yang telah diuraikan maka dapat ditarik kesimpulan sebagai berikut:

1. Data yang digunakan dalam analisis ini telah memenuhi asumsi klasik yaitu data berdistribusi normal, tidak terjadi multikolineritas, dan terbebas dari gelaja hetresikditas.

2. Hasil pengujian hipotesis dalam penelitian ini menggunakan satu variabel dependen (Keputusan menabung) dan dua variabel independen (Tingkat Religiusitas dan Kualitas pelayanan) Dan satu variabel moderating yaitu Informasi menunjukan bahwa:

a. pelayanan berpengaruh secara simultan terhadap keputusan mahasiswa menabung pada bank syariah di kota Palu.

b. Pengujian secara parsial bahwa tingkat religiusitas 
tidak berpengaruh secara parsial terhadap keputusan mahasiswa menabung pada bank syariah di kota Palu.

c. Pengujian secara parsial bahwa tingkat kualitas pelayanan berpengaruh secara parsial terhadap keputusan mahasiswa menabung pada bank syariah di kota Palu.

d. Informasi tidak memoderasi hubungan antara tingkat religiusitas terhadap keputusan mahasiswa menabung pada bank syariah di kota Palu.

e. Informasi tidak memoderasi hubungan antara kualitas pelayanan terhadap keputusan mahasiswa menabung pada bank syariah di kota Palu.

Berdasarkan hasil penelitian tersebut, maka diharapkan kepada para stake holder di kalangan kampus IAIN Palu untuk memperhatikan bahwa masih banyak mahasiswa yang menabung pada bank syariah bukan pada sisi religiusitas mahasiswa, namun hanya didasarkan pada kualitas layanan. Oleh karena itu sebaiknya para dosen dan pemegang kebijakan mendorong terlaksananya kegiatankegiatan dan motivasi spritualitas keagamaan agar mahasiswa sadar tentang urgensi bank syariah sebagai bagian dari ketakwaan dan kepatuhan dalam syariah.

\section{Referensi}

http://Finalsial.bisnis.com/read/20160927/90/587449/September 2016, dikutip 4 April 2017.

http://finance.detik com/moneter/3211676/ojk market share, dikutip 4 April 2017.

http://Sulteng.antara news.com/berita /22380/Bi pertumbuhan bank syariah, dikutip 4 April 2017.

Imam, Islachul. Memahami Makna Religiusitas. http://islachul 08.blogspot.co.id/2014/02/pada tanggal 04 April 2017

Kotler, Philip dan kevin Lane Keller. Manajemen Pemasaran. Edisi 3; Surabaya: Erlangga; 2008. 
Masruroh, Atik. Analisis Pengaruh Tingkat Religiusitas dan Diposibble Income terhadap Minat Menabung Mahasiswa di Perbankan Syariah. Semarang: Rosda, 2015.

Qurnia. Yusuf, Quantum Ibadah Mengelola Diri dengan Mengenal Perjalanan Hidup. Solo: Tiga serangkai, 2008.

Salman, Kautsar Riza. Akuntansi Perbankan Syariah Berbasis Psak Syariah. Padang: Akademia, 2012.

Sunyoto, Danang. Metodologi Penelitian Akuntansi. Cet. 1; Bandung: Refika Aditama Anggota Ikapi, 2013.

Umar, Husein. Metode Penelitian untuk Skripsi dan Tesis Bisnis. Jakarta: Rajawali Press, 2011.

Yahya, Rizal, dkk. Akuntansi Perbankan Syariah: Teori dan Praktek Kontemporer. Jakarta: Salemba Empat, 2014.

\section{*Dosen PNS IAIN Palu}

